\title{
Impact of Equipment Support Aid in Nurturing Entrepreneurial Culture
}

\author{
Christabel Divine Brownson \\ Faculty of Social and Management Sciences, Akwa Ibom State University,P.M.B. 1167, Uyo, Akwa Ibom State, \\ Obio Akpa Campus, Oruk Anam, Akwa Ibom State, Nigeria
}

\begin{abstract}
Support has most often been used in a more generic form to represent majority of services provided by the government and other bodies to motivate and aid business startup. However, while there are various studies on different forms of support such as financial support, network support, peer support, counseling support and soft support among others, limited research have been carried out in the area of equipment support offered by the government as a means of encouraging business startup after the training of individuals. Using a descriptive study, 195 participants of entrepreneurship programmes offered by the government in southern Nigeria were examined and findings reveal that to a large extent, the provision of equipment support as a means of promoting entrepreneurship does indeed aid in nurturing entrepreneurial culture in southern Nigeria. The findings contribute new knowledge to the entrepreneurship literature in terms of equipment support provision as a means of aiding business startup. The findings provide implications that will guide government policy decision and other bodies in the offering of entrepreneurship programmes in the region under study.
\end{abstract}

Keywords: Equipment Support, Entrepreneurial Culture, Entrepreneurial Behaviour,

\section{Introduction}

Support has most often been used in a more generic form to represent majority of services provided by the government and other bodies to motivate and aid business startup. However, while there are various studies on different forms of support such as financial support, network support, peer support, counseling support and soft support among others (Benus, 1994; Brown, 1990; Bergmann and Sternberg, 2007; Greene and Storey, 2004), limited research have been done in the area of equipment support. Moreover, given the paucity of data on entrepreneurship support research in Nigeria, this study set out to examine whether the offering of equipment as a means of encouraging entrepreneurship by government agencies responsible for entrepreneurship promotion programmes does aid in the nurturing of entrepreneurial culture.

\section{Entrepreneurial Culture}

Brownson (2013) defines Entrepreneurial Culture as a society that depicts the exhibition of entrepreneurial attributes, entrepreneurial values, entrepreneurial mindset and entrepreneurial behavior among the citizens of such a society which propels them towards entrepreneurship. Bridge et.al (2009) points out that Entrepreneurial Attributes (EA) can be acquired from both nature and nurture as it is essential in influencing the development and realization of startup ideas (Mahadea, 2001). Entrepreneurial Values (EV) are the driving force for decision making (Keeney, 1994) as such, they have important implications not only for the decision to pursue entrepreneurship but also in the way in which the individual entrepreneur approaches a venture (Kilby, 1993).Entrepreneurial Mindset (EM) is a mental attitude which determines how an individual will interpret and respond to situations (Wordweb, 2009). Entrepeneurial Mindset is dynamic in nature hence, it can change across time and from situation to situation (Robinson et al., 1991). Entrepreneurial Behaviour (EB) is referred to as new venture creation, firm birth or startup (Samuelsson and Davidsson, 2009).

\section{Equipment Support and Entrepreneurial Culture}

Extant research have found support services to have a stronger effect in some regions of a country. For instance, Bergmann and Sternberg (2007) found a stronger effect of government support instruments for startups in Eastern Germany than Western Germany as well as Almus (2004) who found that the startup (loans) assistance provided by the government improved employment growth rate. Nevertheless, Patzelt and Shephered (2009) did not find a positive perception of the financial support offered in relation to new ventures as well as Greene and Storey (2004) who found that soft forms of support (signposting) were of little value in moving individuals towards entrepreneurial activity. However, limited research have been carried out on Equipment support and other forms of support on entrepreneurial attributes, values and mindset of individuals receiving such supports. Hence, with dire interest to promote entrepreneurship, will provisions of such support boost entrepreneurial culture in individuals in such a region? 


\section{Research Method}

A posttest- only design with non-equivalent groups was used for this study due to its suitability in settings that does not lend itself for experiments (Agodini and Dynarski, 2004). Using purposive sampling method with a structured questionnaire, data was collected from 195 respondents who participated in the government entrepreneurship programmes. Descriptive statistics was used to analyze the data

\section{Analysis}

The result of the descriptive analysis showing the impact of Equipment Support provided by the government agencies on the constituent of entrepreneurial culture is shown on figure 1 below:

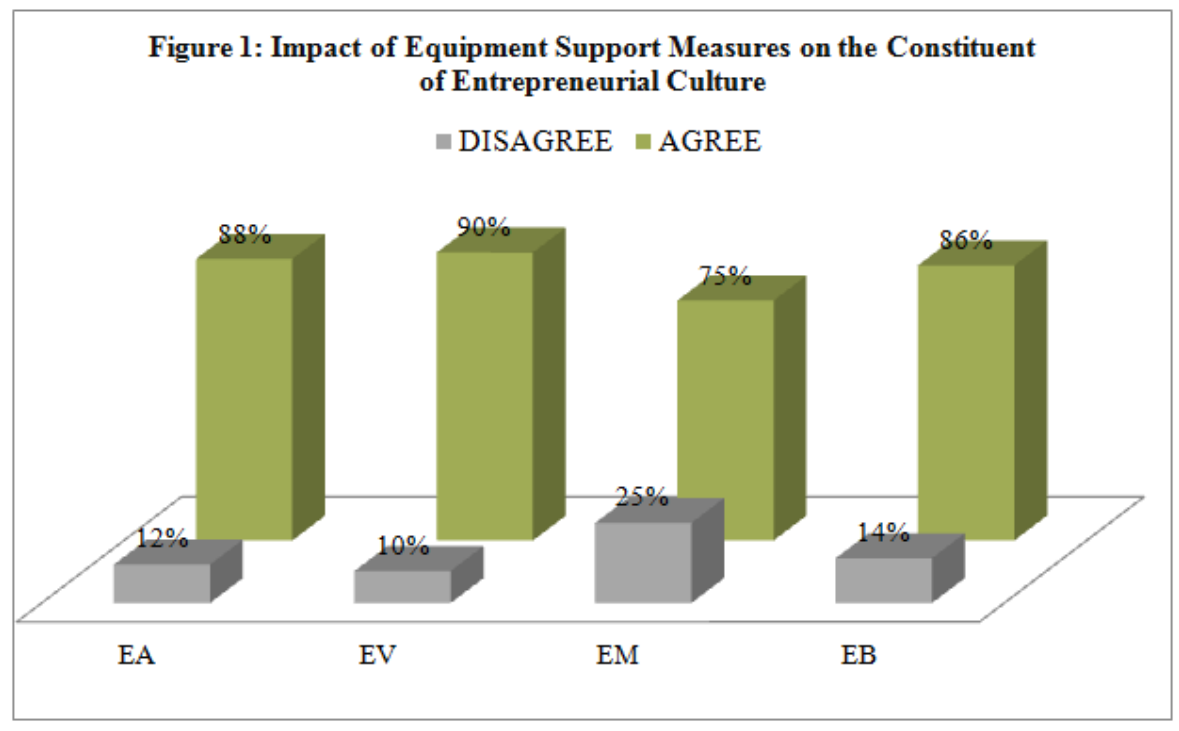

The participants of this policy measures agreed that the Equipment Support provided them by the government did have an impact in fostering the constituent of their Entrepreneurial Culture as indicated by the high level of agreement by the respondents tested. As shown on figure 1, the Equipment Support Measures had a strong impact on the Entrepreneurial Attributes (EA) of the participants to the tuned of $88 \%$ of the respondents who indicated agreement on such impact against the $12 \%$ who disagreed on such impact. The measure also had a strong impact on the respondents' Entrepreneurial Values to the tune of $90 \%$ of those who agreed against the $10 \%$ who disagreed. Similarly, the measures also had a strong impact on the respondents' Entrepreneurial Mindset (EM) and Entrepreneurial Behaviour (EB) to the tune of $75 \%$ and $86 \%$ of the respondents who agreed against the $25 \%$ and $14 \%$ of those who disagreed respectively as shown on the figure. $80 \%$ of the respondents also agreed that the Equipment Support Measures were useful to them compared to the respondents (20\%) who disagreed. The result confirmed the pilot study findings as the respondents in the agencies attested that the Equipment Support Measures provided did nurture the participants' EA (85\%), EV (68\%) and EM (87\%). Although the agencies did not have an accurate data of the new ventures that started during the five year period as a result of the policy measures, a rough estimate of 135 to 1000 new ventures was given albeit, it may not be justifiable. In essence, the results from the two perspectives (participants and the implementers of the Measure government Agencies) of investigation suggest that the provision of Equipment Support by the government agencies in the context studied did contribute to the fostering of the constituent of Entrepreneurial Culture in the recipients of the support during the period under study.

\section{Discussion of Findings}

The finding on the relationship between Equipment Support Measures and the constituent of Entrepreneurial Culture was supported by the descriptive analysis which suggest that the provision of Equipment Support as a measure of Entrepreneurship promotion may likely aid in the nurturing of all the constituent of Entrepreneurial Culture. Though the result from the descriptive analysis supports the pilot study findings and aligns with prior studies for instance, the findings on the relationship between Equipment Support Measure and Entrepreneurial Behaviour agrees with the findings by Bergmann and Sternberg (2007) and Almus (2004) who found support for the influence of government instruments and financial support on startups respectively. The evidence however is not substantial due to the small number of participants who were beneficiary of this aspect of the policy measures. 


\section{Conclusion}

This study set out to examine whether the offering of equipment as a means of encouraging entrepreneurship by government agencies responsible for entrepreneurship promotion programmes does aid in the nurturing of entrepreneurial culture. Through the descriptive analysis used, it can be concluded that Equipment Support Measures offered by governmental agencies in the promotion of Entrepreneurship does have an impact in the fostering of the Entrepreneurial Culture in Akwa Ibom, Nigeria. Though the analysis indicated most support for the objective of the study, the result is constrained by item non-responses and inability to account for other variables. Nevertheless, the result of the analysis did to some extent confirm the pilot findings from the agencies responsible for the implementation thereby adding credibility to the findings of the analysis. The findings of the study adds new knowledge to both the entrepreneurship and public policy literature in that, government effort to promote entrepreneurship by offering Equipment supports to participants of the programme is not wasted but should be encouraged.

\section{References}

[1]. Agodini, R. and Dynarski, M. (2004) ARE EXPERIMENTS THE ONLY OPTION? Review of Economics \& Statistics, Feb2004, Vol. 86 Issue 1, p180-194, 15p

[2]. Almus, M. (2004) JobCreationthroughPublicStart-upAssistance?Applied Economics, 10/10/2004, Vol. 36 Issue 18, p2015-2024, $10 \mathrm{p}$

[3]. Benus, J. M. (1994) Self-Employment Programs: A New Reemployment Tool, Entrepreneurship: Theory \& Practice, Winter94, Vol. 19 Issue 2, p73-85, 13p,

[4]. Bergmann, H. and Sternberg, R. (2007) The Changing Face of Entrepreneurship in Germany, Small Business Economics (2007) 28:205-221, DOI 10.1007/s11187-006-9016-z,

[5]. Bridge, S., O’Neill, K. and Martin, F. (2009) Understanding Enterprise, Entrepreneurship and Small Business, 3rd Edition, Basingstoke: Palgrave Macmillan

[6]. Brown, Robert (1990) Encouraging Enterprise: Britain's GraduateEnterprise Program,Journal of Small Business Management, Oct90, Vol. 28 Issue 4, p71-77, 7p,

[7]. Brownson, C. D. (2011). The Impact of Government Entrepreneurship Promotion Policy Measures in Fostering Entrepreneurial Culture in Akwa Ibom State, Nigeria from 2004 to 2009, Unpublished PhD Thesis, University of Essex, England, 2011

[8]. Brownson, C. D. (2013) Fostering Entrepreneurial Culture: A Conceptualization, European Journal of Business and Management, Vol.5, No.31 (2013).

[9]. Brownson, C. D. (2014) Nurturing Entrepreneurial Culture: Analysis on Akwa Ibom, Lambert Academic Publishing, LAP, Germany (October, 2014) ISBN: 978-3-659-59133-4

[10]. Greene, F. J. and Storey, D. J. (2004) An Assessment of a Venture Creation Programme: The Case of Shell Live Wire, Entrepreneurship\& Regional Development, Mar2004, Vol. 16 Issue 2, p145-159, 15p,

[11]. Keeney, R. L. (1994) Using Values in Operations Research, Operations Research, Vol. 42, No. 5 (Sep. - Oct., 1994), pp. 793-813

[12]. Mahadea, D. (2001) Similarities and differences between male and female entrepreneurial attributes in manufacturing firms in the informal sector in the Transkei, Development Southern Africa, Jun2001, Vol. 18 Issue 2, p189-199, 11p

[13]. Patzelt, H. And Shepherd, D. (2009) StrategicEntrepreneurshipatUniversities: AcademicEntrepreneurs'AssessmentofPolicyPrograms,Entrepreneurship: Theory \& Practice, Jan2009, Vol. 33 Issue 1, p319-340, $22 \mathrm{p}$

[14]. Robinson, P. B., Huefner, J. C. and Hunt, H. K. (1991)EntrepreneurialResearch on StudentSubjectsDoes not Generalize to RealWorldEntrepreneurs,Journal of Small Business Management, Apr91, Vol. 29 Issue 2, p42-50, 9p

[15]. Samuelsson, M. and Davidsson, P. (2009) Doesventureopportunityvariationmatter?Investigatingsystematic process differences between innovative and imitative new ventures,Small Business Economics, Aug2009, Vol. 33 Issue 2, p229-255, 27p,

[16]. Wordweb (2009) Dictionary, Thesaurus and Word Finder Software 